\title{
Editorial
}

\section{Catalysis by Metals on Perovskite-Type Oxides}

\author{
Davide Ferri \\ Paul Scherrer Institut, Forschungsstrasse 111, CH-5232 Villigen, Switzerland; davide.ferri@psi.ch
}

Received: 9 September 2020; Accepted: 11 September 2020; Published: 15 September 2020

Perovskites are currently on everyone's lips and have made it in high-impact scientific journals because of the revolutionary hybrid organic-inorganic lead halide perovskite materials for solar cells. The mixed metal oxide counterparts have received equal interest in a variety of technological applications for decades. The interest for perovskite-type oxides lies in their vast compositional and structural variability that can be exploited to tailor physico-chemical properties such as oxygen mobility and vacancies, redox, as well as electronic and ionic conductivities for specific technical application. Besides oxygen mobility and the variety of element combinations adopting the perovskite-type structure, a further property is interesting for catalytic applications - the possibility to exploit them as a precursor of active catalysts upon exsolution of transition metals in the form of particles at their surface. Transition metals have been shown to experience reversible segregation: Reduced metal nanoparticles are exposed at the moment they need to be used for a catalytic process. The reversible segregation allows their protection from poisoning and growth, thus regenerating the original mixed oxide structure. The interaction between exsolved particles and defective mixed metal oxides also results in potentially new material properties that are difficult to obtain by material synthesis or by combination of the same transition element and other metal oxide supports.

In this Special Issue, various aspects of the synthesis, structure, as well as sorptive and catalytic properties of perovskite-type mixed oxides are presented for a wide range of catalytic processes, demonstrating once more the versatility of this class of materials.

Rojas-Cervantes and co-workers review the utility of perovskite-type oxide-based oxidation catalysts for the treatment of wastewater using various oxidants, as well as ultraviolet-visible irradiation to promote photocatalysis [1]. The authors analyze physico-chemical properties of perovskite-type oxides such as mobility of lattice oxygen and oxygen vacancy formation, stabilizing unusual oxidation states of the contributing elements that can be exploited to enhance advanced oxidation processes $(\mathrm{AOP})$, making use of radicals.

In the contribution of the $\mathrm{PrBaCo}_{2(1-x)} \mathrm{Fe}_{2 \mathrm{x}} \mathrm{O}_{6-\delta}$ layered double perovskite used as an electrocatalyst for the oxygen evolution reaction (OER) in alkaline media, Kim et al. [2] demonstrate the promoting effect of Fe using X-ray absorption spectroscopy. Fe introduction into $\mathrm{PrBaCO}_{2} \mathrm{O}_{6-\delta}$ forces Co to adopt a lower oxidation state to allow for charge compensation. This stabilizes Co and the layered double perovskite against dissolution under the reaction conditions but sustains the formation of the active surface Co oxyhydroxide layer.

Guo et al. [3] demonstrate the feasibility of using $\mathrm{LaCo}_{y} \mathrm{Ga}_{1-y} \mathrm{O}_{3}$ mixed oxides to catalyze the synthesis of alcohols (methanol/ethanol predominantly) from syngas. $\mathrm{La}_{1-x} \mathrm{~K}_{\mathrm{x}} \mathrm{Co}_{0.65} \mathrm{Ga}_{0.35} \mathrm{O}_{3}$ is used as the precursor of segregated Co nanoparticles that are embedded within the La-Ga-O composite oxide, thus improving their stability in the reaction atmosphere. The role of $\mathrm{K}$ is found to increase the atomic dispersion of $\mathrm{Co}$ and improve the coking resistance of the composite catalyst by formation of $\mathrm{La}_{2} \mathrm{O}_{3}$.

In the work by Steiger et al. [4], the reversible segregation of $\mathrm{Ni}$ as an active element for the water gas shift reaction, and a second transition metal is studied to explore the sulfur tolerance in solid oxide fuel cells. Only Fe out of Mn, Mo, Cr, and Fe is found to increase the sulfur tolerance of 
$\mathrm{La}_{0.3} \mathrm{Sr}_{0.55} \mathrm{Ti}_{0.95} \mathrm{Ni}_{0.05} \mathrm{O}_{3 \pm \delta}$. The simultaneous segregation of $\mathrm{Fe}$ and $\mathrm{Ni}$ at high temperature does not hamper the reversible segregation-reintegration of the two metals within the perovskite mixed oxide upon oxidation, allowing for long-term use at high temperature.

Wark and co-workers present the photocatalytic activity of $\mathrm{LaFeO}_{3}$ toward Rhodamine $\mathrm{B}$ decomposition and screen the optimal conditions to obtain the highest performance [5]. Besides textural characterization, photoelectrochemical characterization was exploited to explain the different behavior with calcination temperature, showing that lower temperatures promoted the photo-induced charge carrier transfer and separation efficiency.

A density functional theory study by Glisenti et al. [6] shows that substitution of La by Sr at the A-site of $\mathrm{LaCoO}_{3}$ lowers the formation energy of oxygen vacancies that is beneficial for $\mathrm{CO}$ oxidation in three-way catalysts. Similar effects can be obtained at the B-site only by substitution of Co by $\mathrm{Cu}$. Substitution effects appear to be greater in $\mathrm{SrTiO}_{3}$.

The effect of partial substitution of $\mathrm{Ti}$ in $\mathrm{BaTiO}_{3}$ used as a lean $\mathrm{NO}_{x}$ trap catalyst is studied by Aldridge et al. [7] with respect to the influence on $\mathrm{NO}_{\mathrm{x}}$ storage capacity. Especially, the use of $\mathrm{Cu}$ is beneficial as it promotes the segregation of $\mathrm{Ba}_{2} \mathrm{TiO}_{4}$ and $\mathrm{NO}_{\mathrm{x}}$ storage. $\mathrm{BaTi}_{0.8} \mathrm{Cu}_{0.2} \mathrm{O}_{3}$ exhibits the highest amount of oxygen vacancies and a storage capacity in the range of highly active noble metal-based catalysts.

A series of $\mathrm{LaCo}_{1-\mathrm{x}} \mathrm{Mn}_{\mathrm{x}} \mathrm{O}_{3}$ and $\mathrm{LaCo}_{1-\mathrm{y}} \mathrm{Ni}_{\mathrm{y}} \mathrm{O}_{3}$ catalysts are tested by Rønning and coworkers for $\mathrm{NO}$ oxidation to $\mathrm{NO}_{2}$ that is a crucial step in the production of nitric acid [8]. While $\mathrm{LaCoO}_{3}$ exhibits the highest activity amongst the undoped perovskites, $\mathrm{LaCo}_{0.75} \mathrm{Ni}_{0.25} \mathrm{O}_{3}$ and $\mathrm{LaCo}_{0.75} \mathrm{Mn}_{0.25} \mathrm{O}_{3}$ are found to be optimum in substituted catalysts, showing that perovskites are promising catalysts for $\mathrm{NO}$ oxidation in industrial conditions.

Finally, a three-step reactive grinding process including solid-state synthesis, high-energy ball milling, and low-energy ball milling in wet conditions followed by calcination at $400{ }^{\circ} \mathrm{C}$ is used to prepare $\mathrm{LaMnO}_{3}$ and $\mathrm{LaFeO}_{3}$ by Heidinger et al. [9]. In both cases, the catalytic performance for toluene oxidation increases after each synthesis step of the process in line with the increase in specific surface area that reaches ca. $19 \mathrm{~m}^{2} \cdot \mathrm{g}^{-1}$ for $\mathrm{LaFeO}_{3}$.

I take the opportunity to thank the principal investigators and all authors of the contributed publications for their effort and for willing to make this Special Issue on perovskite-type oxides possible.

Funding: This research received no external funding.

Conflicts of Interest: The author declares no conflict of interest.

\section{References}

1. Rojas-Cervantes, M.L.; Castillejos-Lopéz, E. Perovskites as Catalysts in Advanced Oxidation Processes for Wastewater Treatment. Catalyst 2019, 9, 230. [CrossRef]

2. Kim, B.J.; Fabbri, E.; Castelli, I.E.; Borlaf, M.; Graule, T.; Nachtegaal, M.; Schmidt, T.J. Fe-Doping in Double Perovskite $\mathrm{PrBaCo}_{2(1-x)} \mathrm{Fe}_{2 x} \mathrm{O}_{6-\delta}$ : Insights into Structural and Electronic Effects to Enhance Oxygen Evolution Catalyst Stability. Catalyst 2019, 9, 263. [CrossRef]

3. Guo, S.; Liu, G.; Han, T.; Zhang, Z.; Liu, Y. K-Modulated Co Nanoparticles Trapped in La-Ga-O as Superior Catalysts for Higher Alcohols Synthesis from Syngas. Catalyst 2019, 9, 218. [CrossRef]

4. Steiger, P.; Burnat, D.; Kröcher, O.; Heel, A.; Ferri, D. Segregation of Nickel/Iron Bimetallic Particles from Lanthanum Doped Strontium Titanates to Improve Sulfur Stability of Solid Oxide Fuel Cell Anodes. Catalyst 2019, 9, 332. [CrossRef]

5. Ismael, M.; Wark, M. Perovskite-type $\mathrm{LaFeO}_{3}$ : Photoelectrochemical Properties and Photocatalytic Degradation of Organic Pollutants under Visible Light Irradiation. Catalyst 2019, 9, 342. [CrossRef]

6. Glisenti, A.; Vittadini, A. On the Effects of Doping on the Catalytic Performance of (La,Sr)CoO 3 . A DFT Study of CO Oxidation. Catalyst 2019, 9, 312. [CrossRef]

7. Aldridge, C.; Torregrosa-Rivero, V.; Albaladejo-Fuentes, V.; Sanchez-Adsuar, M.S.; Illan-Gomez, M.J. $\mathrm{BaTi}_{0.8} \mathrm{~B}_{0.2} \mathrm{O}_{3}(\mathrm{~B}=\mathrm{Mn}, \mathrm{Fe}, \mathrm{Co}, \mathrm{Cu})$ LNT catalysts: Efect of partial ti substitution on nox storage capacity. Catalysts 2019, 9, 365. [CrossRef] 
8. Salman, A.R.; Hyrve, S.M.; Regli, S.K.; Zubair, M.; Enger, B.C.; Lodeng, R.; Waller, D.; Ronning, M. Catalytic oxidation of $\mathrm{NO}$ over $\mathrm{LaCo}_{1-\mathrm{x}} \mathrm{B}_{\mathrm{x}} \mathrm{O}_{3}(\mathrm{~B}=\mathrm{Mn}, \mathrm{Ni})$ perovskites for nictric acid production. Catalysts 2019, $9,429$. [CrossRef]

9. Heidinger, B.; Royer, S.; Alamdari, H.; Giraudon, J.M.; Lamonier, J.F. Reactive Grinding Synthesis of $\mathrm{LaBO}_{3}$ (B: Mn, Fe) Perovskite; Properties for Toluene Total Oxidation. Catalysts 2019, 9, 633. [CrossRef] 